\title{
Empirical Analysis of the Conditional Grant Scheme (Cgs) In Delta State, Nigeria
}

\author{
Fredrick OnyebuchiAsogwa (Ph.D.) ${ }^{1}$, EzeaniAishetu Ngozi $^{2}$, \\ Sheriff Urama Musa \\ ${ }^{1}$.Department of Economics, University of Nigeria, Nsukka. \\ ${ }^{2}$.Department of Accounting,Education,Enugu State College of Education(Tech), Enugu,Nigeria. \\ ${ }^{3}$.Department of Business Education, College of Education, Eha-Amufu, Enugu State, Nigeria
}

\begin{abstract}
This study is centered on the impact and process evaluation of the ConditionalGrant Scheme (CGS)in Delta State,Nigeria.The research work adopted the survey method and content analysis due to the nature of the study. Thus the instrument used for data collection includes simple questionnaire and structured interviews. The data collected from the questionnaire were analyzed using frequency tables and simple percentage analysis to check the impact of the projects. The endogenous model of growth was used to explain the relationship between $C G S$ and human welfare. The hypothesis for the study was tested using the chi-square $\left(X^{2}\right)$ method of analysis.The findings of the study show that CGS has contributed significantly to the development of the people as well as the attitude of the people towards the government. The study therefore identified some problems that were responsible for the initial poor involvement to include poor interaction of the government with the people and unfavourable erection sitefor the project. In view of the problems stated above, the study suggested solutions to enhance profitable results and effectiveness in the next line of action.
\end{abstract}

Key words:Millennium Development Goals, Conditional Grant Scheme, Human development, model,poverty

\section{Introduction}

Delta state is one populated at about 4,098,391 as at the 2006 census with a growth rate of $2.33 \%$. it comprises of the Uhrobos, Ijaws, Isokos, Ibos, and the Itshekiris who mainly engage themselves in farming, fishing and hunting as their occupations. With the initiative to improve lives of its people and in compliance with the federal government's strategy to develop as a result of the debt relieve fund and its management in developing the country, Delta state has also contributed up to $50 \%$ of its state fund towards achieving the MDGs-CGS goals for a sustainable life. In view of the areas of improvement centering on health, water, sanitation and education by the OSSAP-MDGs, Delta state has also agreed to participate and also work in conjunction with the UN.

Delta state has been benefiting from the federal government from year 2008, 2009, 2010 and 2011, having satisfied most of the criteria in the 2007 CGS guidelines. Implementation of the projects started and had continued in the cycles of 2008-2009, 2009-2010, 2010-2011. The office of the MDGs and its project support unit coordinates the CGS grants in the state in close working with the parent ministries as well as the state government. The projects are mainly channeled into the provision of; Branded anti-malaria combination therapy; Equipments for PHCs; Staff quarters for PHCs; Solar powered boreholes; Small town water projects; Squat flush toilets; Teaching aids bin schools; Enhanced skill acquisition areas. It was noticed that appropriate due process was used to provide the projects in respective locations by soliciting for bidders displayed at both the government office and the MDGs office, Asaba.

The problem of development has occupied the minds of activists, scholars, political and development workers as well as economists and international organizations for many years with an increased tempo within the last decade. According to Igbuzor (2005), even though there are different perspectives to development, there is a general consensus that development will lead to a good change manifested in increased capacity of people to have control over material assets, intellectual resources and ideology, and obtain physical necessities of life like food, clothing, shelter, employment, etc. This is why some people have argued that the purpose of development is to improve peoples' lives by expanding their choices, freedom and dignity.Nigeria, which was one of the richest 50 countries in the early 1970s, has retrogressed to become one of the 25 poorest countries at threshold of the twenty-first century. (World Bank, 2004).The summary of the project usage s shown in table 1 
Empirical Analysis of the Conditional Grant Scheme (Cgs) In Delta State, Nigeria

Table 1: The summary of CGS project usage in Delta State

\begin{tabular}{|l|l|l|l|l|l|}
\hline Project & Project fund & Total & Implementation & Level of usage & Assessment \\
\hline $\begin{array}{l}\text { Branded anti-malaria combination } \\
\text { therapy }\end{array}$ & 100000000 & 373 & $100 \%$ & $100 \%$ & $100 \%$ \\
\hline Equipments for PHCs & $4,783,498,590$ & 50 & $100 \%$ & $100 \%$ & $100 \%$ \\
\hline Staff quarters for PHCs & $5,890,000,000$ & 62 & $100 \%$ & $73 \%$ & $65 \%$ \\
\hline Solar powered boreholes & $4,783,498,590$ & 19 & $100 \%$ & $93 \%$ & $79 \%$ \\
\hline Small town water projects & 280000000 & 6 & 1005 & $95 \%$ & $80 \%$ \\
\hline Small town water projects & 280000000 & 6 & 1005 & $95 \%$ & $80 \%$ \\
\hline Squat flush toilets & 200000000 & 373 & $100 \%$ & $91 \%$ & $75 \%$ \\
\hline Teaching aids bin schools. & 129500000 & 50 & $100 \%$ & $95 \%$ & $95 \%$ \\
\hline Enhanced skill acquisition areas & $4,783,498,590$ & 2 & $100 \%$ & $100 \%$ & $80 \%$ \\
\hline
\end{tabular}

From the table above, an evaluation was made given the submitted data to the ministry and what is exactly on ground. From the reports given to the parent body on the allocated fund to the state, there existed disparities in the sum, reasons given to corrupt practices as well as over estimation of what is actually needed to fund the project at hand. The column labeled implementation and kevel of usage was given by the state but a personal assessment was made based on the sample carried out earlier on. All the stated projects really has scored beyond average in terms of rating, thus, placing Delta state on a high scale in the implementation of the counterpart fund for the CGS projects. In terms of the project monitoring and erection, the office of the MDGs, ministry of health, ministry of works as well as the state government took as a point of duty to oversee each project.The allocation of the CGS projects and the projects fund are demonstrated with the aid of figure I

Figure I : The CGS projects and its distribution in Delta state

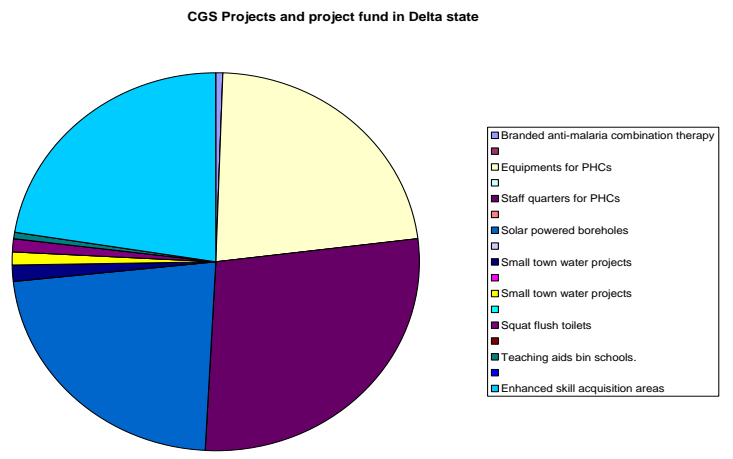

The World is approaching the population of seven billion people, every year; more than 75 million people are being added to the World's population. Almost all of the net population increase-97\%- is in developing countries. With such an increase, the population rate is at a geometric rate of increase unlike her resources which is at an arithmetic rate of increase. Nigeria's population which is speculated to be at over 150 million given to extrapolation will soon run out of funds if reliance is still owed to oil income alone, thus, the need for a conducive environment for the creation for other means of wealth creation which is dependent on the well-being of the citizens. Education and health are basic objectives for development; they are important ends in themselves. At the same time, education plays a key role in the ability of a developing country to absorb modern technology and to develop the capacity for self-sustaining growth and development. Moreover, health is a prerequisite for increases in productivity, and successful education depends on adequate health as well. Thus, they are vital components of growth and development. In the past, much of the planning in Nigeria was centered on the accumulation of physical capital for rapid growth and development, without the recognition of the important role played by human capital in the development process. Since the discovery of oil, the improvement of the agricultural sector has reduced drastically, leaving little assurance of future feeding of the country. There is need for the transformation of the agricultural sector as well as rural development due to the number of rural dwellers in the country.The livelihood of more than half of the economically active population in the developing world directly depends on the environment, wholly or partly through agriculture. This alone underscores the importance of the seventh MDG 'to ensure environmental sustainability. Environmental quality affects, and is affected by, economic development. Environmental degradation can also detract from the pace of economic development by imposing high cost on developing countries through health related expenses and the reduced productivity of resource. Population pressure, inaccessibility of sanitation and clean water mainly affects the poor and is believed to be responsible for the delay in any primary form of development. Also, global warming as well as climate change contributes to a large extent the level of development of any state. This research work is set to provide answers to the following questions;

1. What extent has Conditional Grant Scheme gone in creating job and infrastructural facilities in Delta state? 
2. What is the role of Conditional Grant Scheme in poverty reduction in Delta State?

ObjectiveThegeneral objective is to examine the nature, structure and objective as well as strategies of CGS as an alternative approach for economic growth in Delta state.Specifically, the study is set to achieve the following objectives:

1. To examine the extent to which Conditional Grant Scheme has gone in the creation of job, and increasingof infrastructure facilities in Delta state.

2. To determine the role of Conditional Grant Scheme in poverty reduction in Delta state

Research Hypotheses: Thefollowing hypotheses served as a guide to this study.

Hypothesis 1: Ho: Conditional Grant Schemehas not created significant impact on job creation and enhancement of infrastructurefacilities in Delta state.

Hypothesis 2:Ho:Conditional Grant Scheme has not played major role in poverty reduction in Delta state

\section{Literature Review}

The independent relationships between economic factors and non-economic factors must be within the country's social system to address the issue of growth and development. Resolving the problems to achieve development is a complicated task. Increasing national production, raising levels of living, and promoting widespread employment opportunities are all as much a function of the local history, expectations, values, incentives, attitudes and beliefs. The transition from underdeveloped to more developed economy can be describe as inevitable series of stages which all countrieswill observe. All economies lie within the traditional society made with poor agrarian societies characterized by subsistence ; the pre-conditions for take-off into selfsustaining growth; the take-off stage; the drive to maturity stage ; and the age of high mass consumption. This is in order with the Harrod-DomarGrowth Model. However, new investment representing net additions to capital stocks, investment, labour force growth as well as technological progress are also unavoidable factors. The theory of economic growth states that the rate of growth of GDP is determined jointly by the net national savings ratio, and the national capital-output ratio. Also stating that in the absence of government, the growth rate of national income will be directly or positively related to the savings ratio. Thus with the totality of investment, labour force growth and technological progress, there is possibility of achieving economic growth.

The Structural Change Theory focuses on structural transformation of a primarily subsistence economy. Although this theory was modified by John Fei and Gustav Ranis, the theory was based on a two sector model of a traditional overpopulated rural subsistence sector characterized by zero marginal labour productivity and a high productivity modern urban industrial sector into which labour from the subsistence sector is gradually transferred. This theory focuses on the process of labour transfer and the growth of output and employment in the modern sector.The neocolonial dependence model, false -paradigm model and the dualistic-development thesis came as a result of the disenchantment with both the stages and structural-change model. The see less developedcountries as ones that are facing institutional, political and economic problems and are survived by the dependence and dominance relationship with advanced countries (Mankiw et al 1992)

The U.N. adopted a world development framework known as the MDGs as a millennium declaration which serves as a blueprint for achieving sustainable development in the world, especially in developing countries.The MDGs are eight set aside goals initially launched at the earth summit in Rio de Janeiro in Brazil but was adopted as a working world development framework in the year 2000 at the U.N. Millennium Summit in New York, U.S.A. and launched by 189 Heads of state from the six continents of the world.This was designed to eradicate extreme poverty and hunger;achieve universal basic education; promote gender equality and empowerment of women; reduce child mortality and improve maternal health; combat HIV/AIDS, malaria and other communicable diseases; ensure environmental sustainability; to develop global partnership for development. These goals can only be achieved through effective implementation of the national development framework of each country; the corporate social responsibility efforts of corporate organizations; the cooperation between the government and her citizens. In Nigeria, this gave birth tothe national development framework known as National Economic Empowerment and Development Strategy (NEEDS) with subdivisions in states(SEEDS) and local councils (LEEDS).CGS in Nigeria by 2007 was designed as a measure through which savings made from the debt relief will be expended on projects that supports the Nation's quest for the actualization of the MDGs. Under the 2007 scheme, the projects are narrowed to focus on:Primary health care related projects and programmers' that support child and maternity health; Rural water projects that provide solar power to rural households, local schools and primary health care centers; Rural water supply and sanitation projects located close to, and impacting local primary schools and health clinics; Projects that support and encourage public-private partnership in health, water, and education sectors (Adamu, 2000).

In recent years, economists have explored the empirical relationship across countries and over time between subjectively reported satisfaction and happiness and factors such as income. The crux of the matter is 
centered on sustenance which has to do with the ability to meet basic needs such as food, shelter, health, protection, etc; self-esteem which has to do with being a person with a sense of worth and self-respect, authenticity, identity etc; freedom from servitude which entails one to be able to choose from rule of law, freedom of expression, equality in opportunity etc. As Nigeria plans her revised long term development plan(NEEDS ) in line with the MDGs, the paramount question is 'what are the series of interventions and resource requirements as well as policies and institutions that are needed to achieve the MDGs? According to the presentation on ensuring sustainability of CGS-MDG projects by OSSAP-MDGs on the fifth monthly review meeting in Calabar, 2009, focused on the need to sustain MDG-CGS projects among other developmental areas stressing that MDGs should be sustained beyond 2015 by being subsumed into economic and social agenda of the National and sub-national governments (Offie 2011, Feese 2011 ).

Most of the empirical studies were concerned with only on what the CGS is meant to achieve thereby being limited to its achievements only. In view of this, there is limitation as to the level of use of such studies to carry out some assumptions. They further failed to present any form of problem(s) encountered in terms of providing such projects in communities. The use of the existing work to make inference has become a difficult task because of insufficient number of true population.

\section{Methodology}

Area of Study: This study was carried out in Delta State of Nigeria. This area was used because of the emphasis of the CGS to be used to achieve the said MDGs from the grassroot by the federal government. The government office, ministry of health the office of the millennium development goals, and local government areas were found useful and are all located at Delta State, South-South of Nigeria.

Population of Study: Population refers to a fraction or segment of the target population. It also refers to selected elements (individuals, institutions) by the researcher to represent the true population. The choice of any research method to be used largely depends on the nature, peculiarity of characteristics as well as the objective of the study being researched upon. Thus, the population was chosen from communities (individuals) where these projects were placed and made use of, the focal persons to each local government, permanent secretaries to stated ministries above, all in Delta State.

\section{Source Of Data Collection}

The major sources of data used for this research are grouped into primary and secondary sources. Primary data were obtained through interviews, survey and participant observation while that of the secondary data were obtained from official documents of the CGS-MDG and other related literature.

Sample and Sampling Technique: Sampling is the process of getting a proportion or a fraction part of the population. It is also the process of getting a proportion of the population that will be used to conduct a study. The Taxo Yamani formula was used to determine the sample size.

$\mathrm{n}=\mathrm{N} \div\left[1+\mathrm{N}(\mathrm{e})^{2}\right]$, where $\mathrm{n}$ is the desired sample size; $\mathrm{N}$ is the total population; $\mathrm{E}$ is the margin for error/accepted error limit (5\%); 1 is a constant figure

$\mathrm{n}=62 \div\left[1+62(0.05)^{2}\right]=53.6$

The simple random technique is used to gather samples from the sample institutions. This is because of the nature of the population which shared similar characteristic.

\section{Method of Data Analysis}

The hypothesis was tested using chi-square $\left(\mathrm{X}^{2}\right)$ to validate the hypothesis formulated from the responses to some of the questions from the questionnaire. It is used to test the differences between a set of deserved frequencies for a sample and a corresponding set of expected frequencies. The standard formula for the statistical technique Chi-square is given below as

$\mathrm{X}^{2}=\sum(\mathrm{Fo}-\mathrm{Fe})^{2} / \mathrm{Fe}$, where $\mathrm{X}^{2}=$ Chi-square; $\mathrm{O}=$ observed frequencies; $\mathrm{E}=$ expected frequencies; $\sum=$ summation sign

1. Testing Of Hypothesis One: $\mathrm{H}_{0}$ : Conditional Grant Scheme has not created significant jobs, and infrastructure facilities in Delta state.

$\mathrm{H}_{1}$ : CGS has impacted significantly on the human development of its targets in Delta State

\section{Contingency Table for Hypothesis One}

\begin{tabular}{|c|c|c|c|c|c|}
\hline Options & OF & $\mathrm{EF}$ & OF-EF & $(\mathrm{OF}-\mathrm{EF})^{2}$ & $\begin{array}{l}(\mathrm{OF}-\mathrm{EF})^{2} \quad \square \\
\mathrm{EF}\end{array}$ \\
\hline Yes & 60 & 50.42 & 9.58 & 91.78 & 1.82 \\
\hline No & 2 & 0.32 & 1.68 & 2.82 & 8.82 \\
\hline Yes & 57 & 47.90 & 9.1 & 82.81 & 1.73 \\
\hline No & 5 & 0.80 & 4.2 & 17.64 & 22.05 \\
\hline Yes & 29 & 24.37 & 4.63 & 21.44 & 0.88 \\
\hline No & 23 & 3.67 & 19.33 & 373.65 & 101.81 \\
\hline Yes & 54 & 45.38 & 8.62 & 74.30 & 1.64 \\
\hline
\end{tabular}




\begin{tabular}{|c|c|c|c|c|c|}
\hline No & 8 & 1.28 & 6.72 & 45.16 & 35.28 \\
\hline
\end{tabular}

$\mathrm{X}^{2}$ calculated $=174.03$

To calculate the $\mathrm{X}^{2}$ critical value, we first of all calculate the degree of freedom $(\mathrm{df})$ using the formuladf $=(\mathrm{r}-1)(\mathrm{c}-$ $1)$, where $r$ is number of rows; $c$ is number of columns; $d f=(4-1)(2-1) ; d f=(3)(1) ; d f=3$. The $X^{2}$ critical value is 7.8147

Decision rule: Reject the null hypothesis $\left(\mathrm{H}_{0}\right)$ if the $\mathrm{X}_{\text {cal }}^{2} \square \mathrm{X}_{\text {tab }}^{2}$ or accept the alternative hypothesis. Inferences: Since the $X^{2}$ cal, 174.03 is greater than the $X^{2}$ critical value 7.8147. we reject the $H_{0}$ and accept $H_{1}$. This implies that CGS has impacted significantly on the human development of its targets in Delta State. It has created job and infrastructural facilities in Delta state.

Test of Hypothesis Two: $\mathrm{H}_{0}$.poor involvement of the masses, poor funding and poor targeting has no negative effect on the achievement of CGS projects

$\mathrm{H}_{1}$. Poor involvement of the masses, poor funding and poor targeting has negative effect on the achievement of CGS projects in poverty reduction in Delta state.

\section{Contingency Table for Hypothesis Two}

\begin{tabular}{|l|l|l|l|l|l|}
\hline Options & OF & EF & OF-EF & OF-EF) & \\
\hline Yes & 61 & 47.59 & 13.41 & 179.83 & OF-EF) ${ }^{2} \square$ EF \\
\hline No & 1 & 0.22 & 0.78 & 0.6084 & 3.78 \\
\hline Yes & 48 & 37.45 & 10.55 & 111.3025 & 2.77 \\
\hline No & 14 & 3.08 & 10.92 & 119.25 & 2.97 \\
\hline Yes & 57 & 44.47 & 12.53 & 157.00 & 38.72 \\
\hline No & 5 & 1.10 & 3.9 & 15.21 & 3.53 \\
\hline Yes & 27.5 & 21.46 & 6.04 & 36.48 & 13.83 \\
\hline No & 34.5 & 2.58 & 724.69 & 1.70 \\
\hline
\end{tabular}

$$
\begin{aligned}
& \mathrm{X}^{2}=\sum(\mathrm{OF}-\mathrm{EF}) \square \mathrm{EF} \\
& \mathrm{X}^{2}=162.91
\end{aligned}
$$

Thus, to find the $\mathrm{X}^{2}$ critical value, we first of all calculate the degree of freedom using the formular: $\mathrm{Df}=(\mathrm{r}-$ 1)(c-1)

$$
\text { Df }=(4-1)(2-1)=3
$$

To determine $\mathrm{X}^{2}$ critical value, we look for the level of significance in the $5 \%$ case against degree of freedom at 3 in the chi-square table. The value is 7.8147 Decision rule: Reject null hypothesis $\left(\mathrm{H}_{0}\right)$ if $\mathrm{X}_{\text {cal }}^{2}$ is greater than the $\mathrm{X}_{\text {tab }}^{2}$ and accept otherwise.

Inferences: Since $\mathrm{X}^{2}$ cal is 162.91 is greater than $\mathrm{X}_{\text {tab }}^{2}$, we reject the null hypothesis, thus accepting the alternative hypothesis.Thus, we agree that poor involvement of the masses, poor funding and poor targeting has negative effect on the achievement of CGS projects.

\section{Project Constraint}

In the bidding, funding, disseminating, erecting, positioning, managing of all project, different constraints were witnessed. Most of which are; getting exactly what the people wanted, the positioning of the projects for easy access, getting the right contractor to properly execute the project with the right funding with cost at mind, maintenance and sustainability. These constraints in their own way delayed some of the projects one way or the other but all have been put in place and the next task is maintenance.

\section{Summary}

This paper is centered on the impact of the CGS projects and the involvement of the people as well as government in the provision of these projects in Delta state. The study looked at CGS as a comprehensive home policy designed to improve the living standard of the people in the state. It sees CGS as a viable economic policy which if well implemented will enhance sustainable development and welcome investors in Nigeria.The data collected for the study was mainly primary such as questionnaires and oral questioning with a supplement of secondary data from reports from the parent office as well as online. Because of the nature of the study, the researcher adopts simple random sampling method while Tara Yamani formula was used to determine the sample size.The researcher used a simple percentage analysis and frequency distribution table to analyze the responses of the respondents on interviews and questionnaire instrument. The hypotheses for the study were tested using the chi-square method.The analysis of the study showed that CGS has impacted positively on the people of Deltastate. Poor funding, poor targeting and poor participation were factors identified to be constraints to the achievement of the policy.The study went further to state answers to the constraints witnessed in the erection of the projects. Sensitization, seminars and interactions were parts of the suggested solutions to the identified constraints. 


\section{Recommendations}

The following solutions are very important for effective implementation of Conditional Grant Scheme in Delta State.

(i) There is need for wider advertisement for more bidders as well as competition so as to get the best contractors that will be able to execute the job.

(ii) There is need for grass root interaction between the people and the government in order to find out the actual needs of the people

(iii) .Sensitization process must be carried out in order to make the people aware of the presence of the project as well as whom the project is meant for.

(iv) The initiative of community users group is important in order to the make the community aware that the project belongs to them. The community should not waite for government in terms of the projects' maintenance.

(v) There is need for a control mechanism to keep the agencies responsible for the execution of the projects.

\section{References}

[1] Adamu C. etals (2000): democracy and development. Political Institutions and well-being of the World.I Tech pub. New York

[2] Baro C. J. (1991) Economic Growth and School Enrolment Unipress New York, USA

[3] Philip A. Black, EstianCalitz, and Tjaart J. Steenekamp (1999), "Public Economics For

[4] South African Students. Southern Africa: Oxford University Press, pp.249-269..

[5] Goulet d. (1991): Economic Development. London Macmillian Publishers

[6] Mankiw, Romer N. and Wet J.O. (1992) Savings, Investment and Population Growth. An Empirical Approach Tech. Publishers, Canada

[7] National Population Commission (2006): NPC Report on Census Conducted. Abuja, Nigeria

[8] Shonubij. (2004) : NEEDS/SEEDS/LEEDS Based Strategy on CGS. FML press Abuja.

[9] TodaroC.and Smith (2010). Economic Development.United Nations commission for Africa 2008 